\title{
Congenital generalised bone dysplasias: a clinical, radiological, and epidemiological survey
}

\author{
POUL ERIK ANDERSEN JR AND MOGENS HAUGE \\ From the Department of Diagnostic Radiology, Odense University Hospital; and the Institute of Clinical \\ Genetics, Odense University, Denmark.
}

SUMmARY The point prevalence at birth of generalised bone dysplasias was estimated by a study of all children born between 1 January 1970 and 31 December 1983 in the county of Fyn (Denmark). Additionally the population prevalence on 31 December 1983 of all patients with generalised bone dysplasias in this county was determined. The county is a well defined, representative subregion of Denmark which demographically comprises a cross section of about $9 \%$ of the Danish population.

In total, bone dysplasias were found to be more frequent than generally assumed. Achondroplasia was, however, less common with a point prevalence at birth of 1.3 per 100000 , while osteogenesis imperfecta (21.8), multiple epiphyseal dysplasia tarda (9.0), achondrogenesis $(6 \cdot 4)$, osteopetrosis $(5 \cdot 1)$, and thanatophoric dysplasia $(3 \cdot 8)$ were found more frequently. It is striking how many bone dysplasias are still erroneously classified as achondroplasia. Correct diagnosis is important for a valid prognosis, for treatment, and for genetic counselling. The diagnosis relies almost exclusively on the radiographical findings.

Comprehensive epidemiological studies, based on total populations, are difficult to perform for geographical and administrative reasons. The available reports on generalised bone dysplasias are few and incomplete ${ }^{12}$ and quite elementary epidemiological data are missing. Many of the conditions are difficult to study satisfactorily because they are hard to diagnose and thus often misclassified, or because they remain undiagnosed, especially in stillborn babies and in children dying shortly after birth.

The county of Fyn (Funen) forms a geographically and administratively well defined region, which, with regard to area and population, comprises about $9 \%$ of Denmark. Analyses of a number of demographic, economic, social, and health conditions have established that the population constitutes a representative cross section of the Danish population. Thus, this county is very suitable for epidemiological investigations.

\section{Materials and methods}

The investigation consisted of two parts: (1) the determination of the point prevalence at bith, including all newborn children (livebirths and still-

Received for publication 1 February 1988.

Revised version accepted for publication 27 April 1988 births, that is, those born dead after the end of the 28th gestational week) with generalised bone dysplasias, delivered between 1 January 1970 and 31 December 1983 to mothers with a permanent address in the county; and (2) the population prevalence of generalised bone dysplasias in all who were alive on 31 December 1983 and had a permanent address in the county. The generalised bone dysplasia (intrinsic bone anomaly) should have been present at birth though it might have escaped observation until later in life. Bone changes secondary to endocrinological disorders, inborn errors of metabolism, malnutrition, organ failure, and chromosome defects have not been included and abortions were disregarded in this study.

Ascertainment of patients was performed through a central computerised inpatient register for the period 1 April 1973 to 31 December 1983. All discharge diagnoses from the 10 hospitals in the county have been entered in this register since 1 April 1973. Before this date, cases were collected from the files of all surgical, obstetrical, paediatric, and orthopaedic departments of each of the hospitals in the county as far back as diagnostic archives were kept. Furthermore, the diagnostic archive of the $x$ ray department at Odense University Hospital was searched right back to its establishment in 1956. 
This archive includes inpatients as well as outpatients. In all cases of bone dysplasia, irrespective of the certainty of the diagnosis, the case records, $x$ ray pictures, necropsy reports, and histological descriptions, as well as any filed genetic records available, were perused. When bone dysplasia was found or suspected, a detailed family history was obtained in all cases by contacting the probands or their closest relatives and, if necessary, by calling them in for supplementary clinical and radiological examinations. Data on all first degree relatives were considered indispensable in all cases. Only when complete accordance between the clinical, radiological, pathological and genetic findings was present was the diagnosis considered definite and the patient entered into the study.

\section{Results}

The results are given in the table. In the period 1 January 1970 to 31 December 1983 a total of 77977 children, including stillbirths, was born in the county of Fyn. Fifty-five of these had generalised bone dysplasia which gives a point prevalence at birth of 75.7 per 100000 . On 31 December 1983 the population of Fyn amounted to 453921 , of whom

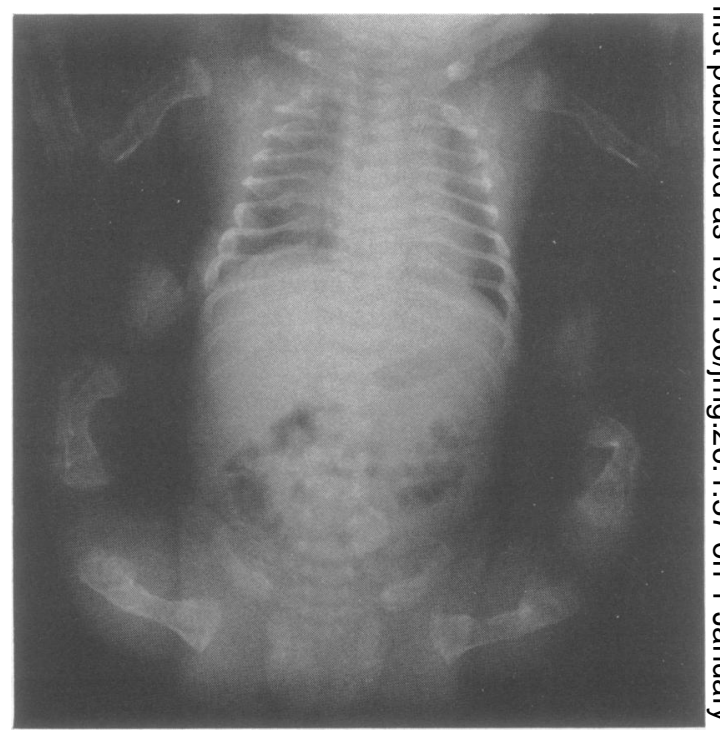

FIG 1 Osteogenesis imperfecta type II. The baby died shortly after birth. Multiple fractures and deformity of all long bones, many ribs, and vertebral bodies, and severe osteoporosis.

TABLE Generalised bone dysplasias in the county of Fyn (Funen), Denmark.

\begin{tabular}{|c|c|c|c|c|c|}
\hline & $\begin{array}{l}\text { Born 1.1.70- } \\
31.12 .83\end{array}$ & Death & $\begin{array}{l}\text { Alive on } \\
31.12 .83\end{array}$ & $\begin{array}{l}\text { Point prevalence } \\
\text { at birth } \\
\text { (per } 100000)\end{array}$ & $\begin{array}{l}\text { Prevalence on } \\
31.12 .83 \\
(\text { per } 100000)\end{array}$ \\
\hline \multicolumn{6}{|l|}{ Osteogenesis imperfecta } \\
\hline I & 12 & 0 & & & \\
\hline II & 2 & 2 & 48 & $21 \cdot 8$ & $10 \cdot 6$ \\
\hline III & 2 & 0 & & & \\
\hline IV & 1 & 0 & & & \\
\hline Achondroplasia & 1 & 1 & 5 & $1 \cdot 3$ & $1 \cdot 1$ \\
\hline Hypochondroplasia & 1 & 0 & 2 & $1 \cdot 3$ & 0.4 \\
\hline Thanatophoric dysplasia & 3 & 3 & 0 & $3 \cdot 8$ & 0 \\
\hline \multicolumn{3}{|l|}{ Achondrogenesis } & 0 & $2 \cdot 6$ & 0 \\
\hline III & 2 & 2 & 0 & $6 \cdot 4$ & 0 \\
\hline IV & 3 & 3 & 0 & 0.4 & 9 \\
\hline Asphyxiating thoracic dysplasia (Jeune) & 2 & 2 & 1 & $2 \cdot 6$ & $0 \cdot 2$ \\
\hline Chondrodysplasia punctata (Conradi-Hünermann) & 1 & 1 & 2 & $1 \cdot 3$ & $0 \cdot 4$ \\
\hline Campomelic dysplasia & 1 & 1 & 0 & $1 \cdot 3$ & 0 \\
\hline Multiple cartilaginous exostoses & 10 & 0 & 39 & $12 \cdot 8$ & $8 \cdot 6$ \\
\hline Multiple epiphyseal dysplasia tarda & 7 & 0 & 18 & $\mathbf{9 \cdot 0}$ & $4 \cdot 0$ \\
\hline Metatropic dysplasia & 0 & 0 & 2 & - & $0 \cdot 4$ \\
\hline \multirow{2}{*}{\multicolumn{6}{|c|}{$\begin{array}{l}\text { Metaphyseal chondrodysplasia (Schmid) } \\
\text { Spondyloepiphyseal dysplasia }\end{array}$}} \\
\hline & & & & & \\
\hline Tarda, brachyarchitic (Lenz) & 2 & 0 & 3 & $2 \cdot 6$ & $0 \cdot 7$ \\
\hline Pseudoachondroplastic (type I, Kozlowski) & 0 & 0 & 1 & - & $0 \cdot 2$ \\
\hline Pseudoachondroplastic (type III) & 0 & 0 & 1 & - & $0 \cdot 2$ \\
\hline Osteopetrosis (non-lethal) & 4 & 0 & 27 & $5 \cdot 1$ & 5.9 \\
\hline Unclassifiable lethal micromelic dysplasia & 2 & 2 & 0 & $2 \cdot 6$ & 0 \\
\hline Total ( $95 \%$ confidence limits) & $59(44-74)$ & $19(11-28)$ & $150(126-174)$ & $75 \cdot 7(58 \cdot 7-92 \cdot 8)$ & $33 \cdot 0(21 \cdot 7-44 \cdot 3$ \\
\hline \multirow{2}{*}{\multicolumn{6}{|c|}{ 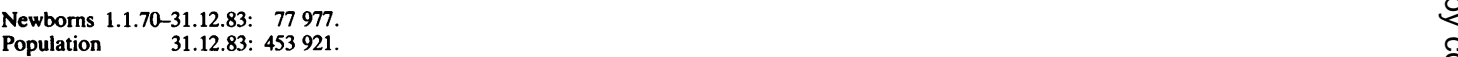 }} \\
\hline & & & & & \\
\hline
\end{tabular}


150 had generalised bone dysplasia. Thus, the prevalence is 33.0 per 100000 . The distribution of the dysplasias over the years was even; there was no conspicuous geographical accumulation and no significant sex difference.

Osteogenesis imperfecta constitutes by far the largest group with a point prevalence at birth of 21.8 ( $95 \%$ confidence limits 12.7 to 31.0 ) and a population prevalence of $10.6(4 \cdot 2$ to $17 \cdot 0)$ per 100000 . Both values are far higher than previously reported. ${ }^{3}$ Classification in the four types was performed according to Sillence et al. ${ }^{34}$ Radiographical examples of types II, III, and IV are given in figs 1 to 4 .

Achondroplasia was found to be much less frequent than generally assumed ${ }^{5}$ and with a lower prevalence at birth $(1.3(0$ to $3 \cdot 5))$ than achondrogenesis $(6.4(1.4$ to 11.4$))$, multiple epiphyseal dysplasia (MED) tarda (9.0 (3.1 to $14 \cdot 9))$, autosomal dominant osteopetrosis $(5.1(0.7$ to 9.5$))$, and thanatophoric dysplasia $(3.8(0$ to $7 \cdot 6))$. Only one patient with achondroplasia was born in the period 1 January 1970 to 31 December 1983. Of the remain-

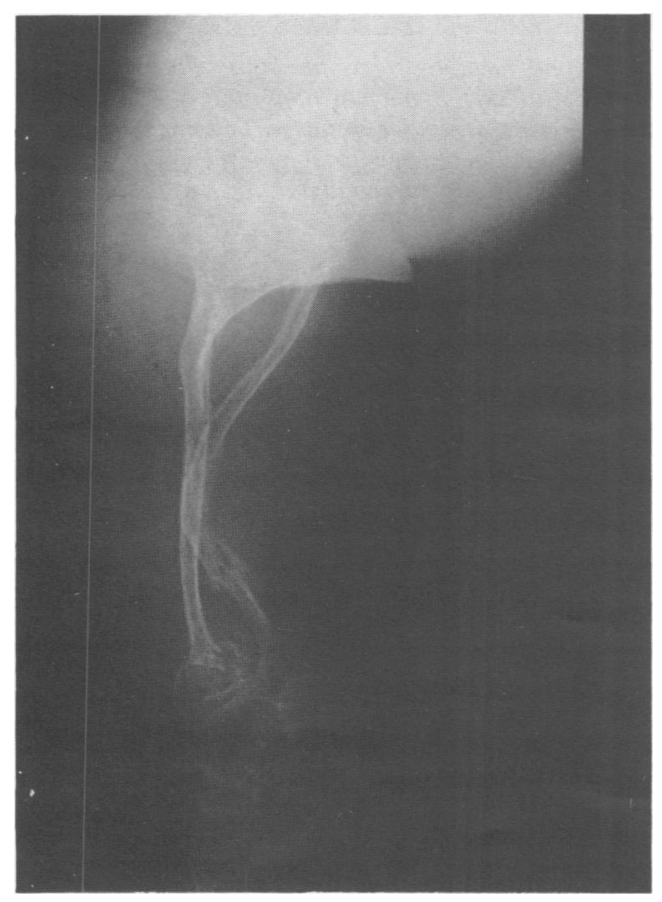

FIG 2 Osteogenesis imperfecta type III. Woman of 69 years. Right crus with severe deformity, osteoporosis and thin diaphyses. Progressive deformity of spine and long bones with age.

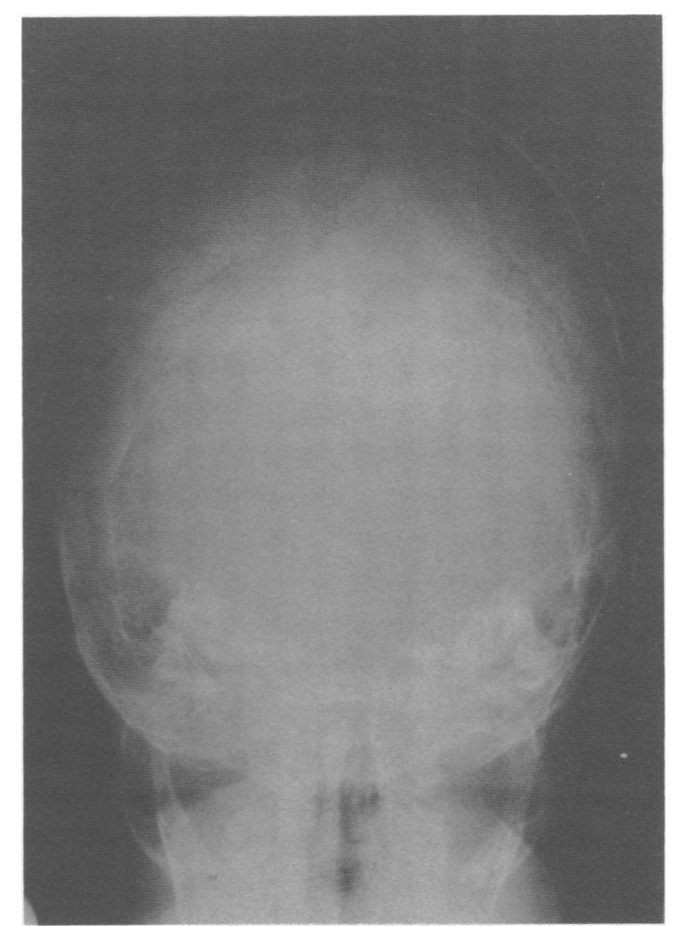

FIG 3 Osteogenesis imperfecta type IV. Boy of two years. Wormian bones. There was generalised osteoporosis, dentinogenesis imperfecta, and normal coloured sclerae.

ing 58 patients, 13 had erroneously been classified under the diagnosis of achondroplasia.

One of the three patients with thanatophoric dysplasia had cloverleaf skull.

Micromelic bone dysplasia with cloverleaf skull has been described earlier. ${ }^{6}$ This dysplasia has similarities to thanatophoric dysplasia, achondrogenesis type IV, and achondroplasia, but is different from these and should probably be looked upon as a separate entity.

Achondrogenesis has been classified into four types according to length/width of the femur. ${ }^{7}$ Following this, two (identical twins) were classified as type $\mathrm{III}^{8}$ and three as type IV. Two were originally erroneously diagnosed as achondroplasia, both clinically and histologically, and one as thanatophoric dysplasia.

Two of the cases of asphyxiating thoracic dysplasia (Jeune) were sibs. The first born was erroneously diagnosed as achondroplasia. As both parents were phenotypically normal and unrelated, it was incorrectly concluded (on the basis of the wrong diagnosis) that a dominant mutation was likely to be the 


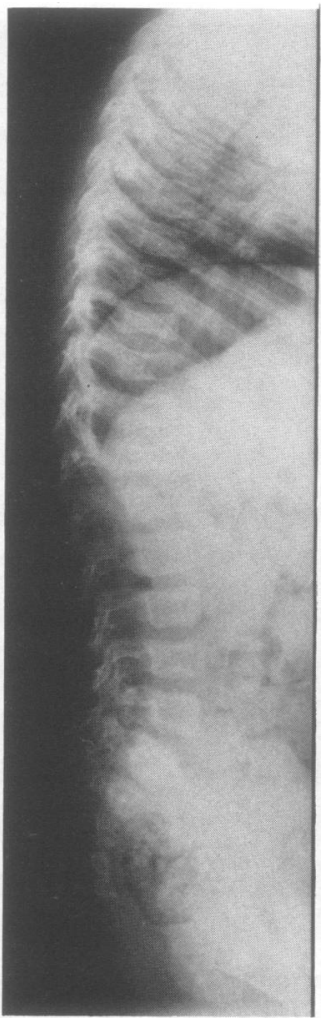

FIG 4 Osteogenesis imperfecta type IV. Same patient as in fig 3, aged two years. Osteoporosis and several fractured vertebral bodies.

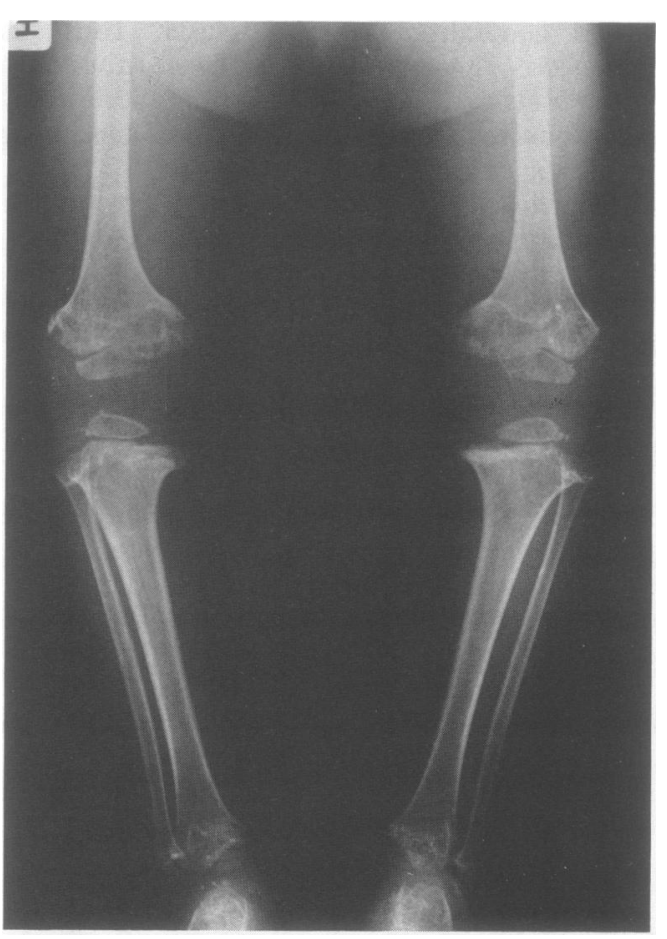

FIG 6 Spondyloepiphyseal dysplasia-pseudoachondroplasia type I (Kozlowski). Same patient as in fig 5. Age five and a half years. Irregular epiphyses and metaphyseal flaring. Triangular shaped distal femoral epiphysis wedged $\stackrel{\overline{\mathrm{O}}}{\exists}$ into a wide $V$ shaped intercondylar notch of the femoral metaphysis. Genu varum.

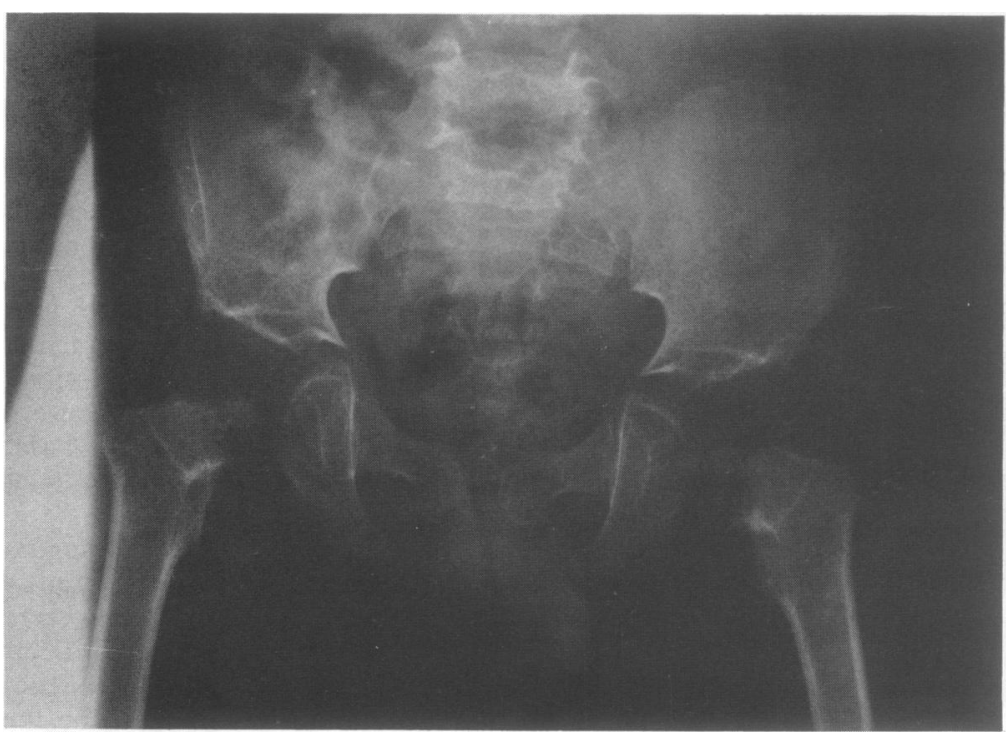

FIG 5 Spondyloepiphyseal dysplasia-pseudoachondroplasia type I (Kozlowski). Age three and $\bigcirc$ a half years. Delayed appearance, $\mathrm{\omega}$ underdevelopment, and irregular ossification of femoral heads. Acetabular cavities dysplastic. 


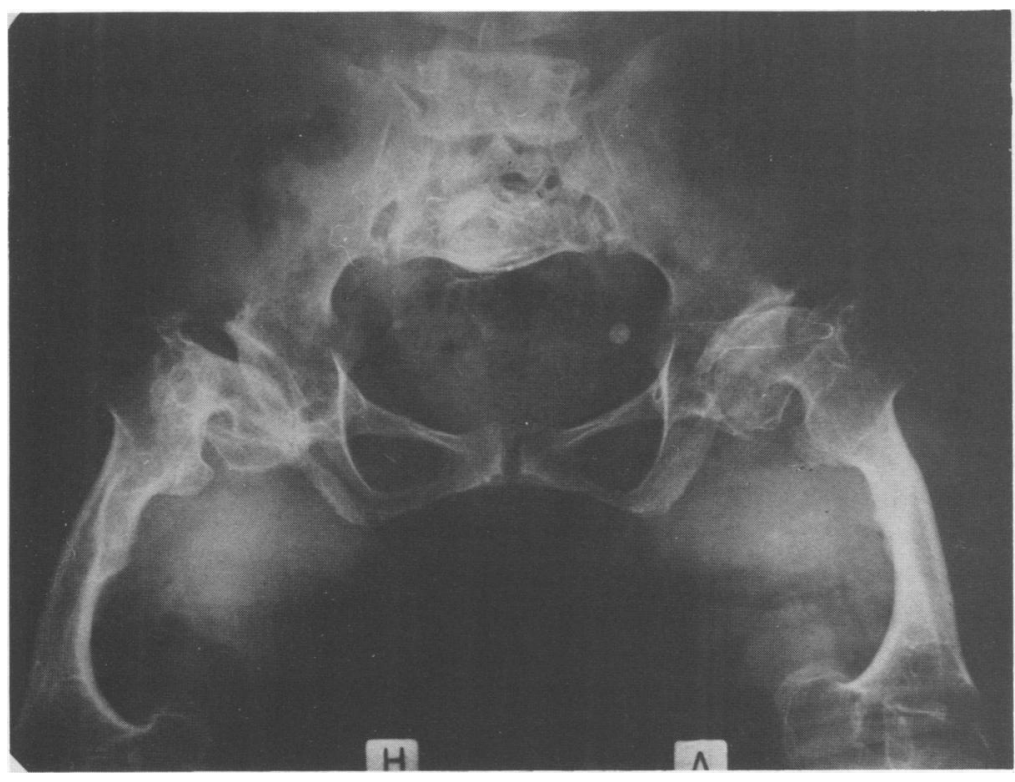

FIG 7 Spondyloepiphyseal dysplasia-pseudoachondroplasia type III. Age 56 years. Severe deformity of hips with coxa vara and short femora with wide metaphyses. Bow legs, short limbs in relation to trunk, and normal face and head.

cause. Consequently, the recurrence risk was not assumed to be increased. However, a diagnosis of asphyxiating thoracic dysplasia, which is an autosomal recessive trait, was made retrospectively when the parents had another child with the same bone dysplasia.

Four of the patients with MED tarda were first cousins; two of these and four other cases were for a long time wrongly diagnosed and treated as bilateral Legg-Perthes disease until the correct diagnosis was made.

Spondyloepiphyseal dysplasia tarda and pseudoachondroplasia were classified according to Bailey ${ }^{9}$ and Wynne-Davies $e t a^{10}$ (figs 5 to 8).

The three cases of spondyloephiphyseal dysplasia tarda were a mother and her two sons.

Autosomal dominant osteopetrosis was also found to be more frequent than previously assumed. ${ }^{11}$ The cases of osteopetrosis could be classified radiologically into two types ${ }^{12}$ : type I, characterised by sclerosis, mainly of the calvarium and to a lesser degree of the vertebral arches and other parts of the skeleton. The vertebral bodies were almost normal (figs 9 and 10). Type II showed characteristic sclerosis of the end plates of the vertebral bodies ('sandwich' vertebrae or 'rugger jersey' spine) and to a lesser degree of the cranial base and tubular bones. The calvarium was almost normal (figs 11 and 12). All patients could be classified into one of these two types, 18 into type I and nine into type II. There was no significant sex or

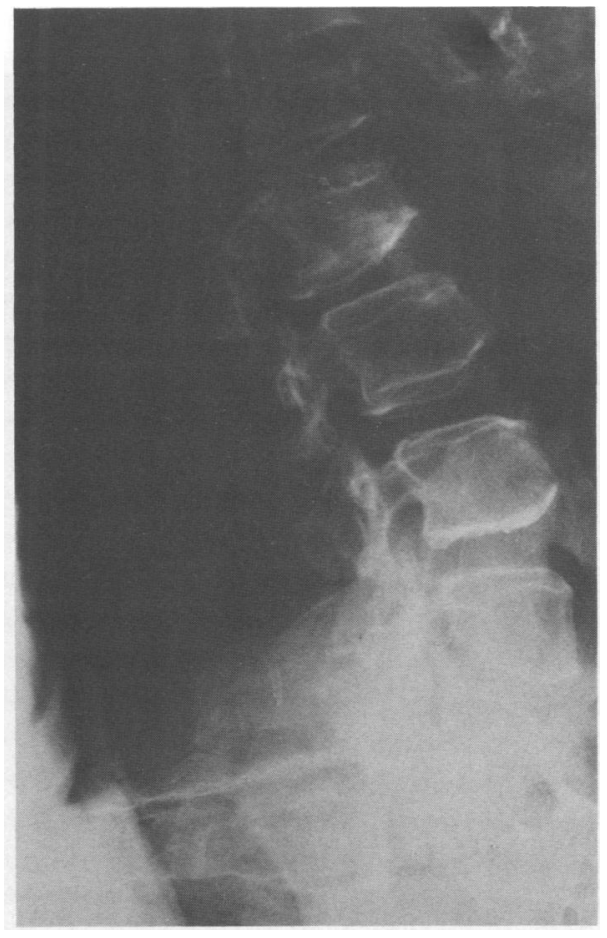

FIG 8 Spondyloepiphyseal dysplasia-pseudoachondroplasia type III. Same patient as in fig 7, aged 57 years.

Irregular vertebral bodies in lumbar spine with narrow anterior portions. 


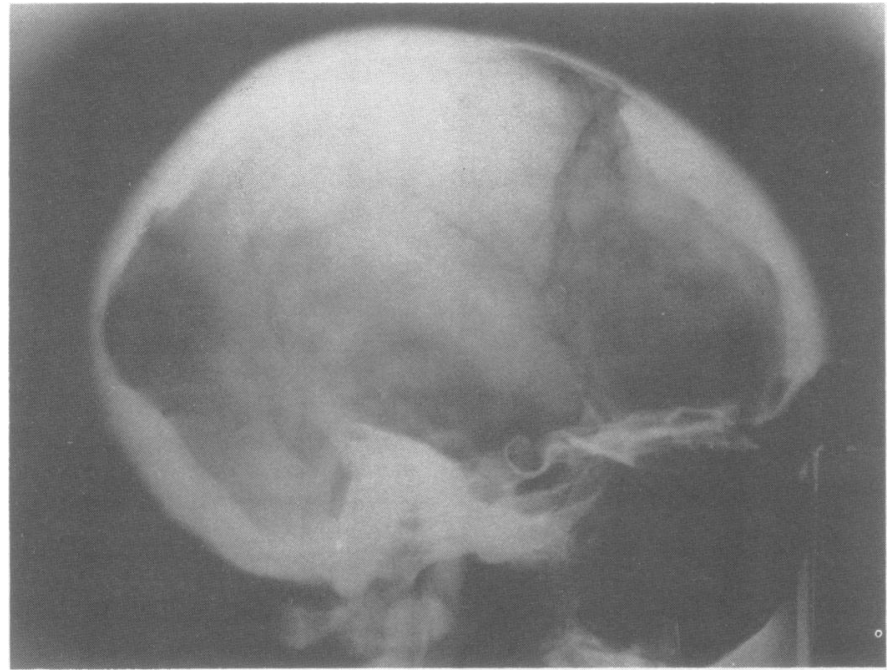

FIG 9 Osteopetrosis type I. Skull with pronounced sclerosis of the vault. Age 20 years.

age difference between the types. Within a given family, only the same type was found.

Two cases of neonatal lethal micromelic dysplasia were unclassifiable as $x$ rays were not obtained.

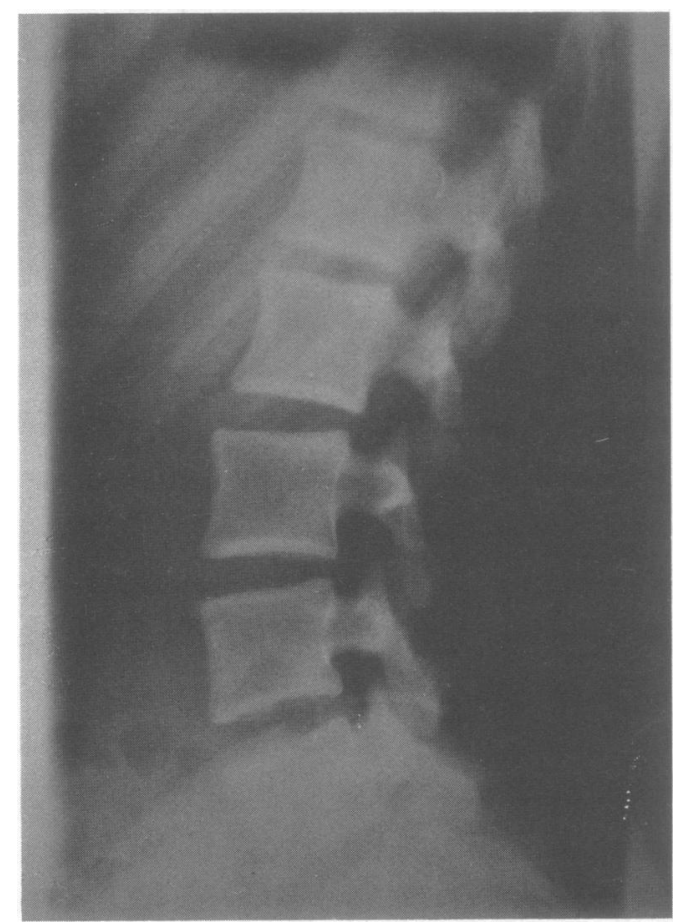

FIG 10 Osteopetrosis type I. Same patient as in fig 9, aged 20 years. Slightly diffuse sclerosis of the lumbar spine.

\section{Discussion}

The ascertainment of patients was based on all available inpatient registers as well as the radiologio cal register at Odense University Hospital, whict comprises both inpatients and outpatients. Furth ermore, detailed family histories and examination were performed. One-third of the patients were ascertained from the radiological register and fron $\vec{\Phi}$ family examinations. Thus, ascertainment is con 3 sidered as complete as possible, but complete as certainment of all bone dysplasias is probably no

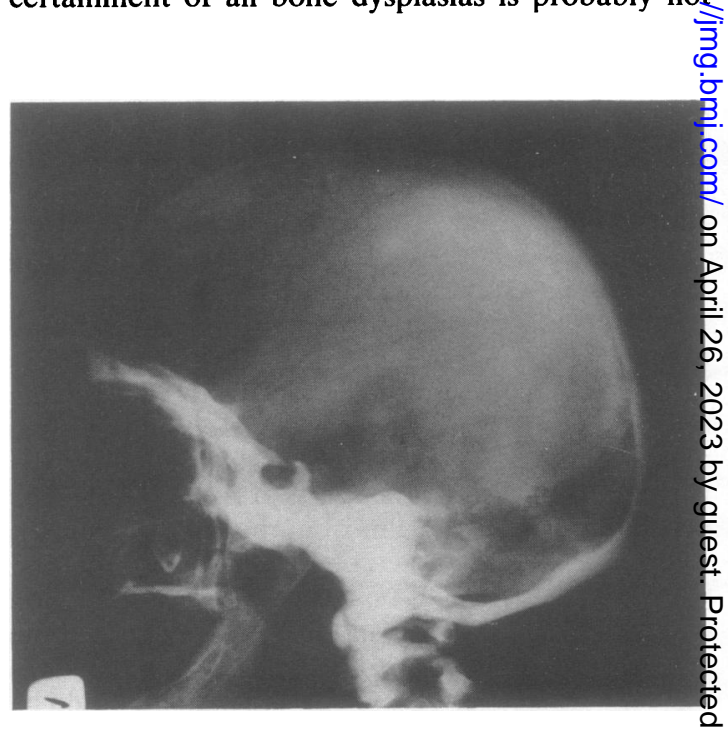

FIG 11 Osteopetrosis type II. Almost normal cranial vault but sclerosis of the base. Age 24 years. 


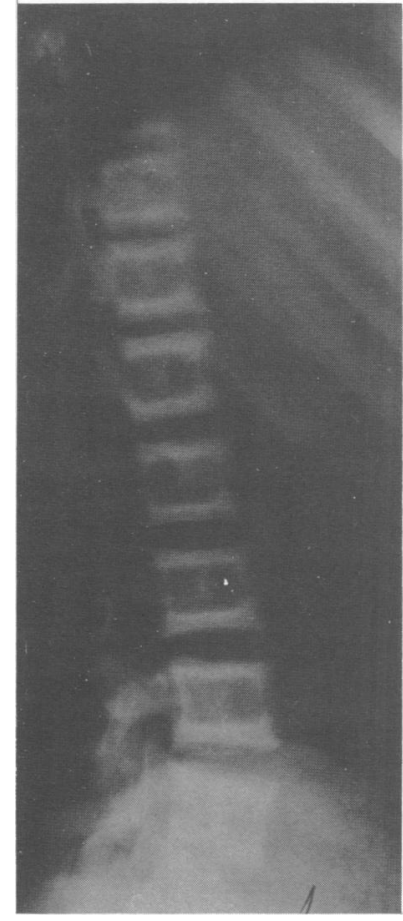

FIG 12 Osteopetrosis type II. 'Sandwich' or 'rugger jersey' spine. Age 15 years.

possible. In particular, dysplasias with no or very few symptoms are likely to be underrepresented as these will often not be examined. However, the clinical importance of such dysplasias is minor.

By a thorough and systematic investigation of a population sample, it has been shown that generalised bone dysplasias are more common than generally assumed and that the distribution of the individual types differs markedly from what is commonly described. Achondroplasia, however, has been found to be less common, while other bone dysplasias, formerly included among the achondroplasias, have been found to have a higher prevalence. A very high prevalence of osteogenesis imperfecta was found. The demographic characteristics which are controllable do not show any differences from the other Danish counties and no indications of a higher coefficient of inbreeding were found in the county. No indications of clusters were observed. Thus, no special genetic or environmental regional conditions are considered to be the cause of the high prevalences.

The error in the estimates of the population prevalence is greater the longer back in time we go, as radiographical documentation is missing in a larger number of cases because it was formerly uncommon to obtain $x$ rays of newborn and stillborn infants with suspected bone dysplasia. The point prevalence at birth calculated from the period 1 January 1970 to 31 December 1983 is assumed to be as exact as possible, as knowledge of the bone dysplasias has grown and the patients are more carefully examined, including $x$ ray examinations at birth. A few conditions like multiple cartilaginous exostoses, osteopetrosis (autosomal dominant), osteogenesis imperfecta types I and IV, and tarda types of spondyloepiphyseal dysplasia and MED are often not diagnosed during the first years of life unless discovered incidentally. Therefore, these groups will probably be underrepresented in the last years of the study period. However, all patients from the study period are at present over four years old, and therefore conditions which are not immediately obvious at birth will have been recognised by now in most cases.

The characteristic stippling in the epiphyses in chondrodysplasia punctata will often disappear during the first year of life. ${ }^{13}$ If the diagnosis is not made until then, these patients will often erroneously be classified as MED tarda or brevitas extremitatis inferioris unilateralis (in cases of the Conradi-Hünermann type) later on.

Multiple cartilaginous exostoses is usually only diagnosed when the exostoses are symptomatic and so is probably underrepresented.

When osteopetrosis is suspected, $x$ ray examinations of the skull and spine as well as the pelvis and tubular bones should be obtained, as sclerosis is located mainly in the calvarium (type I) or the end plates of the vertebral bodies (type II). The radiological findings in the spine in type II resemble the findings in hyperparathyroidism or in uraemic osteodystrophy ('rugger jersey spine'), but blood analysis in patients with osteopetrosis excludes these conditions.

Many cases of MED tarda and spondyloepiphyseal dysplasia tarda are erroneously diagnosed as Legg-Perthes disease and even treated as such. When bilateral Legg-Perthes disease is suspected, supplementary $x$ ray examination of the spine and other joints to exclude generalised epiphyseal disease should be performed before treatment is instituted. ${ }^{14}$

The radiological findings in generalised bone dysplasias are often characteristic and an exact diagnosis can be made. Even in cases where the therapeutic possibilities are few or non-existent, a correct diagnosis is important for valid genetic counselling and evaluation of the clinical prognosis. This again can influence therapy. ${ }^{15}$ It is therefore 
important in cases of congenital malformations including skeletal abnormalities and dwarfism to obtain $x$ ray pictures of the whole skeleton as soon as possible in order to make a correct diagnosis.

As the bone dysplasias are individually relatively rare, it is difficult for most hospitals to obtain sufficient experience in diagnosing individual cases. There is a need for sufficiently large regional centres collecting cases which will improve knowledge and service in a field which includes many patients with a severe, lifelong, or even lethal handicap.

We thank Dr Jens Bollerslev for cooperation on the osteopetrosis patients. The study was supported by a grant from 'Forskningsfonden vedr Medfødte Sygdomme under Vanførefonden'.

\section{References}

${ }^{1}$ Wynne-Davies R, Gormley J. The prevalence of skeletal dysplasias. An estimate of their minimum frequency and the number of patients requiring orthopaedic care. $J$ Bone Joint Surg (Br) 1985;67:133-7.

2 Orioli IM, Castilla EE, Barbosa-Neto JG. The birth prevalence rates for the skeletal dysplasias. J Med Genet 1986;23:328-32.

${ }^{3}$ Sillence DO, Senn A, Danks DM. Genetic heterogeneity in osteogenesis imperfecta. J Med Genet 1979;16:101-16.

${ }^{4}$ Sillence D. Osteogenesis imperfecta: An expanding panorama of variants. Clin Orthop 1981;159:11-25.

5 Oberklaid F, Danks DM, Jensen F, Stace L, Rosshandler S.
Achondroplasia and hypochondroplasia. J Med Genet 1979 16:140-6.

${ }^{6}$ Kozlowski K, Warren PS, Fisher CC. Cloverleaf skull wit generalised bone dysplasia. Report of a case with short review of the literature. Pediatr Radiol 1985;15:412-4.

${ }^{7}$ Whitley CB, Gorlin RJ. Achondrogenesis: new nosology wit evidence of genetic heterogeneity. Radiology 1983;148:693-8.

${ }^{8}$ Andersen PE Jr. Achondrogenesis type II in twins. Br J Radio 1981;54:61-5.

${ }^{9}$ Bailey JA II. Disproportionate short stature. Diagnosis and management. Philadelphia: Saunders, 1973.

10 Wynne-Davies R, Hall CM, Apley AG. Atlas of skeletat. dysplasias. Edinburgh: Churchill Livingstone, 1985.

" Johnston CC Jr, Lavy N, Lord T, Vellios F, Merrit AD, Deiss WP. Osteopetrosis. A clinical, genetic, metabolic and morpho logic study of the dominant inherited, benign form. Medicine (Baltimore) 1968;47:149-67.

12 Andersen PE Jr, Bollerslev J. Heterogeneity of autosomal dominant osteopetrosis. Radiology 1987;164:223-5.

13 Andersen PE Jr, Justesen P. Chondrodysplasia punctata. Reports of two cases. Skeletal Radiol 1987;16:223-6.

14 Crossan JF, Wynne-Davies R, Fulford GE. Bilateral failure of the capital femoral epiphysis: bilateral Perthes disease, multiple epiphyseal dysplasia, pseudoachondroplasia, and spondy loepiphyseal dysplasia congenita and tarda. J Pediatr Ortho $1983 ; 3: 297-301$.

15 Poznanski AK. Bone dysplasias: not so rare, definitely important. AJR 1984;142:427-8.

Correspondence and requests for reprints to $\mathrm{Dr} P$ Andersen Jr, Department of Diagnostic Radiologyo Odense University Hospital, DK-5000 Odense Denmark. 